\title{
Potential Mainland Chinese Cruise Travelers' Expectations, Motivations, and Intentions
}

Abstract: The global cruise industry is the fastest growing sector in the entire leisure market. Due to the limited development of the Chinese cruise sector and government controls on outbound travel, the cruise, especially the outbound cruise, is a new concept in China. Few studies have addressed Chinese consumers' perceptions of cruises. This study aimed to explore the preferences of potential Chinese cruisers and their expectations, motivations, and intentions in relation to taking an outbound cruise. This study also proposed and tested a conceptual framework: the Expectation, Motivation, and Intention (EMI) Model. Data were collected in Beijing and Shanghai; 242 valid responses were received. The results partially supported the proposed model. The theoretical and practical contributions of the study are discussed.

Keywords: cruise, expectation, motivation, intention, EMI Model, China

\section{Introduction}

The worldwide cruise industry is the fastest growing sector in the entire leisure market, with an average annual passenger growth rate of 7.4 percent (Florida Caribbean Cruise Association, 2010). The cruise industry has been characterized by significant growth even during the well-documented financial downturn of recent years (Gibson \& Papathanassis, 2010). According to the Cruise Lines International Association (2010), the total number of cruise travelers was 9.53 million in 2003 and increased to 13.44 million in 2009. The industry's growth was exemplified by the Caribbean, which continues to rank as the dominant cruise destination, accounting for 37.02 percent of all itineraries in 2009 (Cruise Lines International Association, 2010).

Due to the limited development of the Chinese cruise sector and restrictive tourism policies in the past, cruising is a new concept to China. The country has a relatively small (compared to total population) but fast growing middle class, and these people will become interested in cruising when they perceive it as a conspicuous consumption or a status symbol (Wei, 2004). In 2009, there were one million cruise travelers from Asia, 200,000 of which came from China. It is predicted that the number of cruise travelers from Asia will reach two million by 2015 (Cruise Lines International Association, 2010). Many scholars believe that the number of Asian cruise travelers will increase dramatically because over 85 million Chinese now have the ability to take international vacations (Josiam, Huang, Spears, Kennon, \& Bahulkar, 2009). Even if only 1 percent of Chinese tourists choose a cruise trip over other vacation alternatives, this figure would help to double the world's cruise traveler population. The Chinese government has also designated the cruise industry as a main economic growth pillar for the coming 5 years (Anonymous, 2010).

Many international cruise companies view Asia, especially China, as an essential 
market. The Asia Pacific Marketing and Sales Director of Costa Cruises pointed out that China is the company's biggest challenge because the Chinese market directly affects the performance of Asia. Thus, the Chinese market is an important part of Costa Cruises' long-term development. Costa Cruises was the first international cruise company to enter the China market in 2005, and it offers various cruise products, such as short haul family trips, in order to gain more customers (Anonymous, 2010).

All of the cruise products provided by the top three travel agencies authorized to conduct outbound tours in China are outbound travel packages. The main destinations are the Caribbean (11-15 days), the Mediterranean (10 days), Southeast Asia (6-8 days), Antarctica and South America (20 days), and the Middle East (10 days). All of these cruise products include flights from Beijing, Shanghai, or Guangzhou to or from one of the destination cities or harbors.

Given the opportunities presented by the Chinese cruise market, it is necessary to explore the preferences, expectations, motivations, and intentions of potential Chinese cruisers. Some research has been conducted on the motivations of cruise travelers in Asia, including Hong Kong (Qu \& Wong, 1999) and Taiwan (Josiam et al., 2009). However, few studies have addressed the motivations of potential Mainland Chinese cruisers (Fu, Huang, \& Cai, 2010). As indicated by Gorham and Rice (2007), a cruise is not a one-size-fits-all type of product; thus, the preferences and motivations of cruise travelers reported in Western countries may not be the same as those in Mainland China. Furthermore, travelers' expectations of cruising have not been well studied, regardless of the geographic location of the market. Therefore, the objectives of this study were to (1) assess the behavioral preferences of potential cruise travelers in China; (2) examine the expectations, motivations, and intentions of potential Chinese cruisers; (3) test the structural relationship of expectation, motivation, and intention; and (4) derive practical suggestions for cruise operators and travel agents.

\section{Literature Review}

\subsection{Expectation}

The concept of expectancy refers to the degree of belief that an act will be followed by some consequences (Feather, 1990). What a person does in a situation is assumed to relate to the expectation that the person holds and to the subjective value of the outcomes that may occur following the action (Feather, 1982). In other words, a person chooses a certain behavior for its expected results (Hsu, Cai, \& Li, 2010). Expectation is important in the study of tourists' behavior because the importance of tourism activities can be evaluated not only on the basis of need but also on the basis of expected outcomes.

Fluker and Turner (2000) found that expectations were significantly different for participants with and without prior experience in a commercial whitewater rafting experience. 
Their results were also supported by a study on Florida divers (Meisel \& Cottrell, 2003) which found that learner divers are more focused on the diving activity itself. Learner divers are seeking new experiences and new adventures; they are willing to be physically challenged and to be scared. On the other hand, advanced divers generally have more realistic expectations and a more relaxed attitude. They are more concerned with the auxiliary benefits of diving such as meeting new people, using their equipment, and sharing their skills. The results of Meisel and Cottrell's (2003) study indicated that different segments of consumers, in this case based on experience, have different expectations.

\subsection{Motivation}

Motivation has been defined as a state of need or a condition that propels an individual to take a certain action that elicits satisfaction (Moutinho, 2000). Motivation has been referred to as psychological/biological needs and wants, including integral forces that arouse, direct, and integrate a person's behavior and activity (Dann, 1981; Pearce, 1982; Uysal \& Hangan, 1993). People may take a trip to fulfill their physiological (food, climate, and health) and psychological (adventure and relaxation) needs (Mayo \& Jarvis, 1981).

Iso-Ahola (1982) developed a seeking-escaping tourism motivation model. Individuals participate in leisure activities to derive satisfaction by seeking (intrinsic rewards) or escaping (from routine/familiar environments). The Leisure Motivation Scale (Beard \& Ragheb, 1980; 1983; Ragheb \& Beard, 1982), which is a measurement scale derived from Maslow's (1970) motivation theory, has also been adopted widely in travel motivation studies. Beard and Ragheb identified four motives which lead to leisure travel satisfaction: intellectual, social, competence-mastery, and stimulus avoidance.

The push and pull motivation concept has been commonly adopted in studies of tourist behavior (Yoon \& Uysal, 2005). A review of the literature on motivation reveals that people travel because they are "pushed" into making travel decisions by internal psychological forces and "pulled" by the external forces of the destination's attributes (Crompton, 1979). In other words, push motivations are related to the desires of tourists, while pull motivations are associated with the attributes of the destination choices (Crompton, 1979; Dann, 1981). Crompton (1979) identified seven socio-psychological (push) motivations (escape, self-exploration, relaxation, prestige, regression, kinship-enhancement, and social interaction) and two cultural (pull) motivations (novelty and education). However, as motivation is a dynamic concept, it may vary from one person to another, from one market segment to another, from one destination to another as well as from one decision-making process to the next (Uysal \& Hagan, 1993; Witt \& Wright, 1992).

In Lu's (2001) study of Taiwanese cruise travelers, five push and five pull motivation factors were identified. The push factors were lifelong learning, escape and relaxation, adventure, belonging, and status seeking; the pull factors were national environment and safety, 
entertainment and sports recreation, nature and wilderness, learning opportunity, and modernity and facilities. In another study of Taiwanese cruise travelers (Josiam et al., 2009), the core motivating push factors identified were discovery, enjoyment, social esteem, need, escape, and family time. The pull motivation was documented as unifactorial. In a study of Hong Kong cruise travelers' motivations (Qu \& Wong, 1999), the major factors derived were escape from normal life, social gathering, and beautiful environment and scenery.

Fu et al. (2010) studied Chinese cruise tourists' motivations from a cultural-historical perspective and proposed a conceptual model of Chinese cruise traveler motivation. They found that Chinese associations with water in leisure travel, such as life, flow and energy, purity, freshness, and a natural state of being, affected these tourists' motivations. The push factors proposed by $\mathrm{Fu}$ et al. were spiritual purification, moral enlightenment, relaxation and refreshment, escaping, social gathering, family happiness, and cultural discovery; the pull factors included openness, freedom, beautiful scenery, cultural attributes, and entertainment. This model has yet to be examined empirically.

\subsection{Intention}

Intention can be defined as an individual's anticipated or planned future behavior (Swan, 1981). It represents an individual's expectancies about a particular behavior in a given setting and can be operationalized as the likelihood to act (Fishbein \& Ajzen, 1975). When there is an opportunity to act, intention results in behavior. In the context of cruises, Petrick (2004) concluded that quality and perceived value are the antecedents of satisfaction, which leads to behavioral intention. Petrick (2005) also found that visitors who have higher price sensitivity have a higher intention to repurchase cruise products. In addition, critical incidents (Petrick, Tonner, \& Quinn, 2006) and the perceived image of cruise travel (Park, 2006) influence passengers' behavioral intentions.

Intention and motivation are closely correlated as both are important to a traveler's decision in choosing a destination. Hung and Petrick (2011) found that among the motivation items for American cruisers, escape/relaxation contributes the most to intention to cruise, followed by learning/discovery and thrill, self-esteem/social recognition, and bonding, with all four factors substantially and significantly aiding the understanding of cruise intention.

\subsection{Relationships among Expectation, Motivation, and Intention}

Motivation can be conceptualized as the product of expectancy and valence. An individual's motivation to perform a certain activity is a function of the expectation that he or she will be able to perform the activity and obtain the desired outcomes and the personal value of all outcomes associated with that activity (Hsu et al., 2010). Thus, motivation is a product of the individual's expectancy that a certain effort will lead to the intended performance. Hsu et al. (2010) found that a significant positive and causal relationship exists between expectation and motivation among Mainland Chinese travelers to Hong Kong. 
Motivation is a critical element in determining travel behavior; this view is supported by studies that have found that travel motivation affects the intention to revisit a destination or repurchase a travel product. Hung and Petrick (2011) examined the influence of cruising motivation on cruise intention. Their study found a positive relationship between the two variables. This implies that given the same condition, people who have a stronger cruising motivation are more likely to cruise in the future. Despite the general acceptance of the association between motivation and intention, it is critical to further examine the relationship because the correlation may apply to certain, but not all, motivational attributes (Li, Cai, Lehto, \& Huang, 2010). In Li et al.'s (2010) study on American tourists to the countryside, "escape" was the only motivational factor indirectly affecting revisit intention through tourists' affective perception of a destination.

The relationship between expectation and attitude was supported by Hsu et al. (2010), and the relationship between attitude and behavior intention has long been established (Ajzen, 1991). Landry (2003) explored the relationships among self-efficacy, motivation, outcome expectations, and intention certainty. A survey of 441 undergraduate students attending a summer school revealed a positive relationship between outcome expectation and intention, which means a higher outcome expectation will lead to a stronger intention.

Based on the above literature review, a model of expectation, motivation, and intention of cruise travel was proposed (Figure 1) for testing among potential Chinese cruise travelers.

\section{Insert Figure 1 Here}

The model was empirically examined using the following three hypotheses:

H1: Tourists' expectations of a cruise trip have a positive direct effect on their motivations to cruise;

H2: Tourists' motivations for taking a cruise trip have a positive direct effect on their intentions to cruise; and

H3: Tourists' expectations of a cruise trip have a positive direct effect on their intentions to cruise.

\section{Methodology}

Both qualitative and quantitative research methods were used. First, a focus group interview was conducted to explore the attributes of the main constructs under study; then, a questionnaire was used to collect quantitative data. The literature review provided a basis from which to generate items measuring the constructs of expectation, motivation, and intention. However, due to the lack of an available standardized measurement, a focus group interview was conducted to obtain more insights and explore additional measurement items. The results were used in the survey instrument development. The interview group consisted of five 
participants who had all taken a cruise before. The participants (one male and four females) were all of Mainland Chinese origin and between 24 and 30 years old.

The questionnaire devised consisted of three parts. The first part included six general cruise preference questions to identify the most likely combination of products that potential cruisers may choose when there is an opportunity to cruise. The second part included three sets of questions on expectation (14 items), motivation (24 items), and intention (5 items), respectively, using a 7-point Likert-type agreement scale. For the expectation statements, the respondents were asked to indicate their level of anticipation when participating in cruise travel. For the motivation statements, they were asked to indicate the extent to which the statements stimulated their desire to participate in cruise travel. The last part of the questionnaire had seven demographic questions to obtain the profile and characteristics of the respondents. The questionnaire was designed in English and translated into simplified Chinese. The back translation procedure was used. After being translated from English into simplified Chinese by a tourism researcher, the simplified Chinese version was translated back into English by another individual. After the back translation, both language versions of the questionnaire were further refined to make them more precise in terms of expressing the intent of the statements. They were also reviewed by several tourism researchers with competencies in both languages to ensure accuracy of translation.

Before the formal distribution of the questionnaires, a pilot test was conducted to evaluate the quality of the instrument. Twenty Master's degree students in the tourism field from Mainland China were asked to complete the questionnaire in simplified Chinese. In addition, they were asked to evaluate the questionnaire in terms of font size, response choices, and layout. Based on the pilot test results, several modifications were made to make the questions clearer and the layout more user friendly. The questionnaires were distributed in Beijing and Shanghai using a convenience sampling method between 23rd November and 17th December 2010. In total, 250 questionnaires were distributed; 242 completed questionnaires were collected, giving a response rate of 96.8 percent. None of the respondents had ever taken an outbound cruise before, although two of them had experience of domestic cruises.

Data were analyzed using descriptive statistics to provide a demographic and cruise preference profile of the respondents. Exploratory factor analyses were used to reduce the dimensionality of the expectation, motivation, and intention items. Finally, the model and hypotheses were tested via structural equation modeling.

\section{Findings and Discussion}

Before investigating the research constructs, the demographic and behavioral preference profiles of the respondents were examined to provide some contextual information and to accomplish research objective (1). Table 1 shows the demographic profile of the respondents, who were fairly evenly distributed in terms of gender. Over half of the 
respondents were 25 years old or younger, single, and had a college or higher degree. The majority of respondents had never traveled abroad, excluding Hong Kong and Macau (Table 2). The most attractive cruise destination for the respondents was Europe, followed by Southeast Asia and America. A variety of travel-planning time horizons were reported, with 1-2 months in advance being the most popular. Traditional travel agencies remained the most likely channel for booking a cruise, followed by online travel agencies. As for cruise duration, 7-9 days was the most preferred option, followed by 10-15 days and longer than 15 days. The Chinese respondents appeared to enjoy travelling in groups; while 1-3 persons was the most preferred number of travel companions, larger travel party sizes were also popular.

\section{Insert Tables 1 and 2 Here}

\subsection{Expectation, Motivation, and Intention}

Descriptive statistics were used to obtain the mean value of each item under expectation, motivation, and intention. The top expectations were "See some beautiful sceneries" $(\mathrm{M}=6.54)$, "Spend time with friends and family" $(M=6.50)$, "Relax" $(M=6.41)$, "Have fun" $(M=6.17)$, "Experience different cultures" $(M=6.06)$, and "Experience different cuisines" $(M=6.05)$. The results are consistent with earlier research done by Hsu et al. (2010) which emphasized "See some beautiful sceneries" and "Experience different cultures" as two expectation attributes of Chinese travelers. In traditional Chinese culture, family is an important part of human life; parents and children have life-long reciprocal obligations to each other. Thus, spending time with family is expected, including during holidays.

The lowest rated expectation was "Not to be bored" $(M=5.22)$, followed by "Not to get seasick" (M=5.26) and "Build networks and participate in social activities" $(M=5.29)$. This showed that these potential cruise travelers had not thought about being bored or getting seasick. The low mean of "Build networks and participate in social activities" reflected the fact that the respondents did not expect cruise travel to be a good opportunity for networking and social activities. Compared with the second highest mean item, "Spend time with friends and family", interaction with strangers was a much lower priority. According to Hammond and Glenn (2004), the concept of Guanxi identifies people as either insiders and outsiders. In traditional Chinese culture, one is less obligated to share important information with outsiders. While it is natural to have a cohesive and close-knit circle of family and friends, the Chinese are less open to strangers or outsiders.

As for items that would stimulate the desire to cruise (i.e., motivation), the highest mean was "Enjoy beautiful environments and sceneries" $(M=6.36)$, followed by "Experience attractive routes and destinations" $(M=5.99)$, "See and experience new cultures" $(M=5.98)$, "Visit different places in one trip" $(\mathrm{M}=5.86)$, and "Travel to places friends/relatives have not visited" $(M=5.73)$. These results are different from those found in mature cruise markets such as North America. In a study of North American cruisers' motivations (Hung \& Petrick, 2011), 
the most reported motivations for cruising were "To experience other cultures", "To gain knowledge", "To escape", "To give my mind a rest", and "To enjoy activities that provide a thrill". On the other hand, the results of the current study show similarities with other cruise motivation studies conducted in the Greater China area. Such studies have found that the top motivations of other potential ethnic Chinese cruisers (i.e., Hong Kong and Taiwan cruise travelers) include "Enjoy beautiful environments and sceneries", "Experience attractive routes and destinations", and "See and experience new cultures" (Qu \& Wong, 1999; Josiam et al., 2009). "Visit different places in one trip" and "Travel to places friends/relatives have not visited" are also motivational factors for Taiwanese cruisers, although no specific mean values were reported by Josiam et al. (2009). "Travel to places friends/relatives have not visited" is an expression of discovery and self-esteem. Travelers can share first-hand information with others when they return home and enjoy the pleasure of being admired. "Sharing travel experiences with friends" is also one of the most important motivation factors for Mainland Chinese travelers to Hong Kong (Hsu \& Lam, 2003). These parallel findings show that sharing information with close friends and enjoying their admiration is a very important travel motivation among Mainland Chinese travelers, especially in the early years of a particular travel destination or product.

The lowest motivation rating was for "Enjoy casino experience" $(M=2.81)$, followed by "Enjoy health and exercise" $(M=4.28)$ and "Visit friends or relatives who live in the destination" $(M=4.54)$. The low rating of "Enjoy casino experience" may be explained by the fact that gambling in public is strictly prohibited by law in Mainland China and few people have tried gambling in a commercial setting. Gambling is also perceived as a negative activity in Chinese society (Hsieh, 2002). Thus, to create a socially desirable presentation of self, the respondents may have distorted their responses to rate "Enjoy casino experience" lower (Wood \& Williams, 2007).

With regard to intention to cruise, "I am interested in cruise travel" received the highest rating $(M=5.47)$ and "I intend to cruise in the next three years" had the lowest rating $(M=4.53)$. Although the respondents showed great interest in cruise travel, the level of intention was weaker when the behavior was framed in a specific time period. This may be due to the fact that cruise travel information is limited and the cost of outbound cruise travel is high.

\subsection{Measurement Model}

Before the data was analyzed further, data screening of the expectation, motivation, and intention items was conducted to check for missing data, normality, and outliers. All missing data were replaced with the mean score. As the absolute values of skewness were below 3 and the absolute values of kurtosis were below 8, the data were deemed to be normally distributed (Kline, 2005). As the rating scale was a 7-point Likert-type scale, no outliers were found for this data set. 
Four sets of exploratory factor analyses (EFA) using the principal component method with Varimax rotation were conducted to reduce the dimensionality of expectation, motivation, and intention, respectively. Of the 14 expectation items, 11 were retained in forming two factors (Active Pursuit and Serenity) explaining 58.06 percent of the total variance (Table 3). One item was removed due to cross loading; the other two items were removed due to the low reliability $(\alpha=.16)$ of the factor they formed. The items in the Serenity factor were the three with the highest means, showing that when considering cruise travel, the respondents expected to have a peaceful and relaxing journey more than being active in pursuing diverse experiences.

As the existing literature well documents that motivation is a two-dimensional (Push and Pull) construct, two separate EFAs - one for Push and one for Pull - were conducted. The EFAs reported one-component structures for both the push and pull motivations. Specifically, 6 of the 7 push motivation items were retained, explaining 52.67 percent of the total variance. One item was removed due to a factor loading below 0.4. For the pull motivation, 7 of the 17 items were retained, explaining 47.17 percent of the total variance. Ten items were removed due to a loading below 0.4. Similarly, the EFAs extracted a one-component structure in intention which explained 66.81 percent of total variance.

Confirmatory factor analysis (CFA) was conducted for each construct, followed by the testing of the overall measurement model. According to the previous literature, several indices can be adopted to evaluate model fit. For this type of data set ( 242 as the sample size with 42 observed variables), (a) it is suggested that the Chi-square/degree of freedom should be below 5 (Tabachnick \& Fidell, 2007); (b) it is recommended that the comparative fit index (CFI), normed fit index (NFI), Tucker Lewis Index (TLI), and goodness-of-fit index (GFI) should be greater than 0.9 (Hair et al., 2006); and (c) the root mean square error of approximation (RMSEA) is acceptable when below 0.08 (Browne \& Cudeck, 1993). Two separate second-order CFAs were employed for the expectation and motivation constructs, while two separate first-order CFAs were conducted for the intention construct and the overall measurement model. Table 4 shows the goodness-of-fit indices of all of the measurement models. The fit indices for the final results indicated well-fitted models for the three constructs: the Chi-squares/degrees of freedom were between 2.370 and 3.674, the CFIs between 0.925 and 0.980; the NFIs between 0.878 and 0.973 , the GFIs between 0.916 and 0.966 , the TLIs between 0.905 and 0.960 , and the RMSEAs between 0.075 and 0.105 . The overall CFA model tested also showed a good fit (Chi-square/degree of freedom: 1.715; CFI: 0.984; NFI: 0.962; GFI: 0.966; TLI: 0.974; RMSEA: 0.054).

Table 5 shows the results of the overall measurement model. The standardized factor loadings were between 0.555 and 0.880 (Serenity, an expectation factor, and two intention items were close to or above 0.6 ; the others were all above 0.7 ), and the $t$-values were between 6.484 and 12.347. The reliabilities of all of the latent constructs were acceptable, with construct reliability values between 0.646 and 0.863 . In addition, construct validity was assessed in terms 
of convergent validity and discriminant validity. The Cronbach's alpha values of expectation, motivation, and intention were $0.593,0.747$, and 0.875 respectively, so convergent validity was confirmed. As shown in Table 6, the values of average variance extracted (AVE) were all greater than the squared correlation coefficients, which confirmed good discriminant validity. Thus, the results indicated a well-fitted model which could proceed to the structural model testing stage.

\section{Insert Tables 3, 4, 5 and 6 Here}

\subsection{Structural Model}

The proposed structural model was assessed, and the indices obtained suggested a well-fitted model. Specifically, the NFI was 0.962 , the TLI was 0.974 , the CFI was 0.984 , the GFI was 0.966 , and the RMSEA was 0.054 . Figure 2 shows the structural model with estimated path coefficients. Hypotheses 1 and 2 were supported as significant positive relationships were found between expectation and motivation as well as between motivation and intention. Expectation had a strong positive effect (0.77) on motivation, and motivation also had a significant positive effect $(0.45)$ on intention. Hypothesis 3 was rejected given that an insignificant path was noted between expectation and intention.

\section{Insert Figure 2 Here}

\section{Conclusion and Implications}

This study examined the behavioral preferences of Chinese outbound cruise travelers, and its results can be utilized by cruise companies and travel agencies to meet Chinese cruisers' needs and maximize their profits from this market. For example, respondents reported Europe as the most attractive cruise destination, followed by Japan and Korea and Southeast Asia. The results also showed that most respondents preferred medium length cruises (7-15 days). Cruise companies could develop more regional cruise routes and adjust the schedules to attract consumers' attention.

The most preferred planning time was 1 to 2 months before a cruise. Cruise companies and travel agencies could adjust their pricing strategy based on this time frame (e.g., selling at a non-discounted price 1 to 2 months before the departure date) to maximize their revenue. In terms of booking channels, the respondents still preferred to purchase cruise products from traditional travel agencies. Nowadays, intense competition exists between traditional and online travel agencies. Online travel agencies have become strong competitors to traditional bricks and mortar travel agencies because of their competitive prices and convenient service offerings. However, based on the preferences of the respondents in this study, it appears that traditional travel agencies can still compete with their online counterparts in the Chinese cruise market due to the newness of this holiday mode. Traditional travel agents can provide face-to-face expert advice and much needed information to potential cruise consumers. The situation may change when Chinese travelers gain more cruise experience and when cruises as 
a travel form become more understood.

This study also identified the expectations, motivations, and intentions of potential Chinese cruisers. The top expectation items were "See some beautiful sceneries", "Spend time with friends and family", "Relax" "Have fun", and "Experience different cultures". Cruise operators will need to meet these expectations to generate satisfaction and loyalty. As "Spending time with friends and family" was important and the respondents preferred to travel in groups, it is recommended that cruise operators introduce family/group packages and further enhance on-board facilities and services to satisfy travelers with different characteristics in one party. "Build networks and participate in social activities" was not an expectation for respondents. However, in mature markets, cruises are viewed as a good networking platform, including for business engagements. Cruise operators could raise awareness of this aspect of cruising (e.g., MICE-related use of cruises) to explore additional business opportunities.

The results on motivation indicate that "Enjoy beautiful environment and sceneries", "Experience attractive routes and destinations", "See and experience new cultures", "Visit different places in one trip" and "Travel to places friends/relatives have not visited" are the top five motivations for potential cruisers. The results are similar to those obtained in a study of Taiwanese cruise travelers (Josiam et al., 2009). "Enjoy casino experience" was the weakest motivation reported by potential Chinese outbound cruisers. As for intention, although the respondents showed great interest in cruise travel, not that many intended to take a cruise in the near future. This could be a result of the lack of actual cruise product information. Thus, cruise companies, travel agencies, and destination organizations could cooperate to promote cruise travel and to make more Chinese aware of the availability of cruise travel. Promoters also need to be creative in terms of communication via various media in order to reach different age and lifestyle groups. In the meantime, more international ports could be planned along the coastline of China to expand cruise product offerings.

Academically, this research represents one of the first attempts to develop and empirically test a structural model of cruise travel expectations, motivations and intentions. It contributes to the extant literature by adding expectation into the reported motivation and intention relationship in the cruise context (Hung \& Petrick, 2011). The EMI model, though not empirically fully supported, can serve as a starting point to explore structural relationships among expectation, motivation and intention not only in the cruise context but also in other forms of travel. Previous studies on cruises have focused on mature cruise markets like North America (e.g., Teye \& Leclerc, 1998; Hung \& Petrick, 2011). Few studies have touched on developing cruise markets like Mainland China, which has a huge potential to contribute to the world's cruise industry in the future. Unveiling the characteristics of potential Chinese cruisers provides an addition to the current literature.

The EMI model could also suggest possible ways to increase cruise travel intention. According to the model, motivation has a positive effect on intention. Therefore, when 
promoting cruise products, companies could stimulate potential cruisers' desire by articulating both the internal push and external pull aspects of cruise travel, such as reducing stress from work; enjoying family time together; enjoying different entertainments, shows, and facilities on board; and visiting different destinations in one trip. In addition, expectation positively and directly affects motivation; therefore, operators may want to inform potential cruisers about what they can expect during a cruise. Both serenity and active pursuit related cruise features could raise expectations of cruise travel, which will lead to a stronger motivation to engage in cruise travel.

\section{Limitations and Future Studies}

Based on previous research (Hsu et al., 2010; Fishbein \& Ajzen, 1975; Ajzen, 1991; Hung \& Petrick, 2011), this study empirically identified the interrelations among expectation, motivation, and intention. However, few researchers have looked into cruise expectation and the relationship between expectation and motivation. As a result, most of the items measuring expectation were obtained from the focus group interview, which may not cover all aspects of tourists' expectations of cruise travel. Secondly, the questionnaire was distributed in Beijing and Shanghai using a convenience sample. As tourists' expectations, motivations, and intentions vary among residents in different cities, the findings may not provide a general picture of Mainland Chinese cruisers from different areas. In addition, the research was conducted with a relatively young sample (55.2 percent of the respondents were aged 25 or below). The sampling issue will affect the generalizability of the study's results. Future studies are needed in terms of optimizing sample size and selecting more cities as data collection locations.

\section{References}

Ajzen, I. (1991). The theory of planned behavior. Organizational Behavior and Human Decision Processes, 50, 179-211.

Anonymous (2010, November 10). Italian cruise company, Costa Cruises, coming to China. Top Talent, 58.

Beard, J., \& Ragheb, M. (1980). Measuring leisure satisfaction. Journal of Leisure Research, $12,20-33$.

Beard, J., \& Ragheb, M. (1983). Measuring leisure motivation. Journal of Leisure Research, $15,219-228$.

Browne, M., \& Cudeck, R. (1993). Alternative ways of assessing model fit. In K. A. Bollen \& J. S. Long (Eds.), Testing structural equation models (pp. 257-294). Newbury Park, CA: SAGE Publications. 
Crompton, J. (1979). Motivations for pleasure vacation. Annals of Tourism Research, 6, 408-424.

Cruise Lines International Association, Inc. (2010). 2010 CLIA Cruise Market Overview. Retrieved from http://www.cruising.org/sites/default/files/misc/ 2010FINALOV.pdf

Dann, G. (1981). Tourism motivations: An appraisal. Annals of Tourism Research, 8(2), 189-219.

Feather, N. (1982) Expectations and actions: Expectancy value models in psychology. Hillsdale, NJ: Lawrence Erlbaum.

Feather, N. (1990). Bridging the gap between values and actions: Recent applications of the expectancy-value model. In E. Higgins and R. Sorrentino (Eds.), Handbook of motivation and cognition: Foundation of social behavior (pp. 151-192). New York: Guilford.

Fishbein, M., \& Ajzen, I. (1975). Belief, attitude, intention and behavior: An introduction to theory and research. Reading, MA: Addison-Wesley.

Florida-Caribbean Cruise Association, Inc. (2010). Cruise Industry Overview- 2010. Retrieved from http://www.f-cca.com/downloads/2010-overview-book_Cruise -Industry-Overview-and-Statistics.pdf

Fluker, M., \& Turner, L. (2000). Needs, motivations and expectations of a commercial whitewater rafting experience. Journal of Travel Research, 34, 380-389.

Fu, X., Huang, J., \& Cai, L. (2010). Chinese cruise tourists' motivations - A cultural-historical perspective. In L. Lowry (Ed.), Proceedings of the 2010 Annual International Society of Travel and Tourism Educators (ISTTE) Conference, October 18-22, 2010 on Board Carnival Cruise Line's Paradise (Vol. 22, pp 40-50). St. Clair Shores, MI: International Society of Travel \& Tourism Educators.

Gibson, P., \& Papathanassis, A. (2010). The cruise industry - Emerging issues, problems and solutions: Review of the 2nd International Cruise Conference, Plymouth, UK, 18-20 February 2010. International Journal of Tourism Research, 12, 405-407.

Gorham, G., \& Rice, S. (2007). Travel perspectives: A guide to becoming a travel professional. New York: Delmar Thomson Learning.

Hair, J., Black, W., Babin, B., Anderson, R., \& Tatham, R. (2006). Multivariate data analysis (6th ed.). Upper Saddle River, NJ: Prentice Hall.

Hammond, S. \& Glenn, L. (2004). The ancient practice of Chinese social networking: Guanxi and social network theory. E:CO Special Double Issue, 6 (1-2), 24-31.

Hsieh, C. M. (2002). The policy-making analysis of casino gambling in Penghu County, Taiwan. National Dissertations Database of Taiwan, 90NTU02227017. 
Hsu, C., \& Lam, T. (2003). Mainland Chinese travelers' motivations and barriers of visiting Hong Kong. Journal of Academy of Business and Economics, 11 (1), 60-67.

Hsu, C., Cai, L., \& Li, M. (2010). Expectation, motivation, and attitude: A tourist behavioral model. Journal of Travel Research, 49(3), 282-296.

Hung, K., \& Petrick, J. (2011). Why do you cruise? Exploring the motivations for taking cruise holidays, and the construction of a cruising motivation scale. Tourism Management, 32(2), 386-393.

Iso-Ahola, S. (1982). Toward a social psychological theory of tourism motivation: A rejoinder. Annals of Tourism Research, 9(2), 256-261.

Josiam, B., Huang, T., Spears, D., Kennon, L., \& Bahulkar, G. (2009). Understanding ethnic Chinese travelers on North American cruise tours: Motivations, perceptions, and satisfaction of cruisers. Journal of China Tourism Research, 5, 77-101.

Kline, R. (2005). Principles and practice of structural equation modeling (2nd ed.). New York: Guilford Press.

Landry, C. (2003). Self-Efficacy, motivation, and outcome expectation correlates of college students' intention certainty. Retrieved from Louisiana State University, The Department of Educational Leadership Web site: http://etd.lsu.edu/ docs/available/etd-0409103-084327/

Li, M., Cai, L., Lehto, X., \& Huang, J. (2010). A missing link in understanding revisit intention - The role of motivation and image. Journal of Travel \& Tourism Marketing, 27, $335-348$.

Lu, C. (2001). The study of tourism motivation and experience of the cruise-ship tours - A case study of the Berlitz evaluated 4-star cruise-ships. Masters thesis, Taiwan, Chinese Culture University. Retrieved from http://etds.ncl.edu.tw/theabs /site/sh/detail_result.jsp

Maslow, A. (1970). Personality and motivation. New York: Harper and Row.

Mayo, E., \& Jarvis, L. (1981). The psychology of leisure travel: Effective marketing and selling of travel services. Boston, MA: CBI Publishing Company.

Meisel, C., \& Cottrell, S. (2003). Differences in motivations and expectations of divers in the Florida Keys. 2003 Northeastern Recreation Research Symposium. Newtown Square, PA, US.

Moutinho, L. (2000). Strategic management in tourism. New York: CABI Publishing.

Park, S. (2006). Tapping the invisible cruise market: The case of the cruise industry. Unpublished Doctoral dissertation, Texas A\&M University, College Station.

Pearce, P. (1982). The social psychology of tourist behavior. Oxford: Pergamon Press. 
Petrick, J. (2004). The role of quality, value, and satisfaction in predicting cruise passengers' behavioral intentions. Journal of Travel Research, 42, 397-407.

Petrick, J. (2005). Segmenting cruise passengers with price sensitivity. Tourism Management, 26, 753-762.

Petrick, J., Tonner, C., \& Quinn, C. (2006). The utilization of critical incident technique to examine cruise passengers' repurchase intentions. Journal of Travel Research, 44, 273-280.

Qu, H., \& Wong, E. (1999). A service performance model of Hong Kong cruise travelers' motivation factors and satisfaction. Tourism Management, 20, 237-244.

Ragheb, M., \& Beard, J. (1982). Measuring leisure attitudes. Journal of Leisure Research, 14, 155-162.

Swan, J. (1981). Disconfirmation of expectations and satisfaction with a retail service. Journal of Retailing, 57(3), 49-66.

Tabachnick, B., \& Fidell, L. (2007). Using multivariate statistics (5th ed.). New York: Allyn and Bacon.

Teye, V., \& Leclerc, D. (1998). Product and service delivery satisfaction among North American cruise passengers. Tourism Management, 19(2), 153-160.

Uysal, M., \& Hagan, L. (1993). Motivation of pleasure to travel and tourism. In M. A. Khan, M. D. Olsen, \& T. Var (Eds.), VNR's encyclopedia of hospitality and tourism (pp. 798-810). New York: Van Nostrand Reinhold.

Wei, X. (2004, July 5). China's cruise liner market is small but hopeful. SinoCast China Business Daily News, p. 1.

Witt, C., \& Wright, P. (1992). Tourist motivation: Life after Maslow. In P. Johnson \& B. Thomas (Eds.), Choice and demand in tourism (pp. 33-56). London: Mansell.

Wood, R., \& Williams, R. (2007). Internet gambling: Past, present and future. In G. Smith, D. Hodgins, \& R. J. Williams (Eds.), Research and measurement issues in gambling studies (pp. 491-514). San Diego, CA: Elsevier Publishing.

Yoon, Y., \& Uysal, M. (2005). An examination of the effects of motivation and satisfaction on destination loyalty: A structural model. Tourism Management, 26, 45-56. 


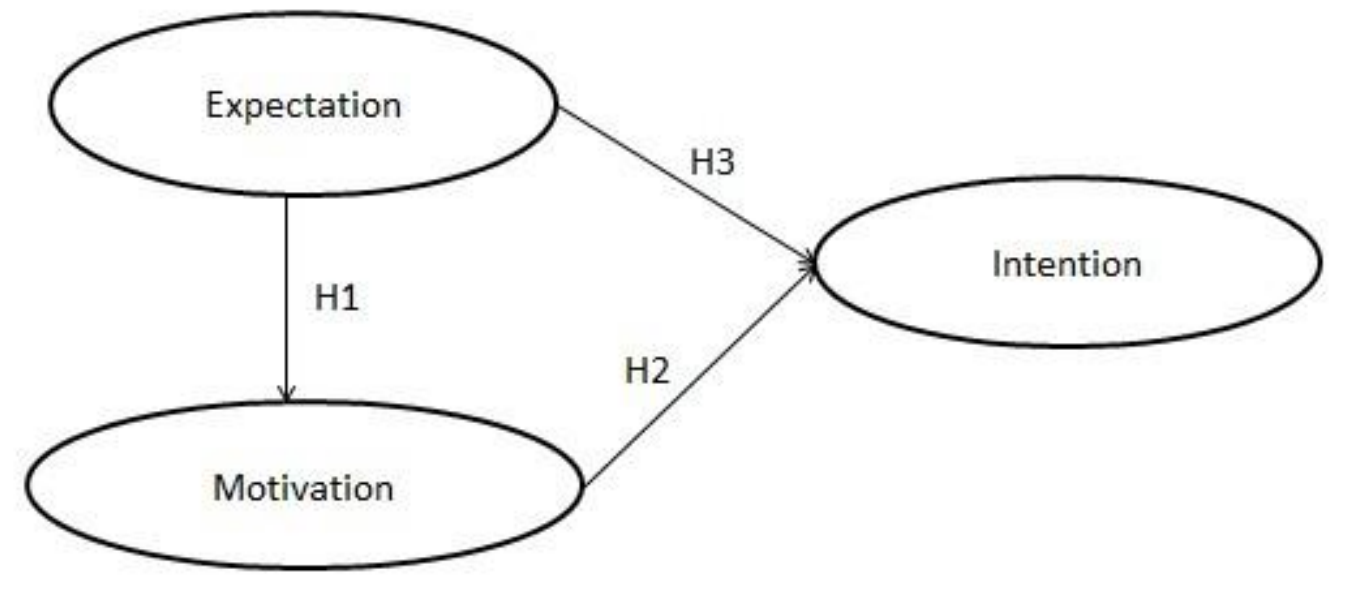

Figure 1. Proposed Model of Expectation, Motivation, and Intention 


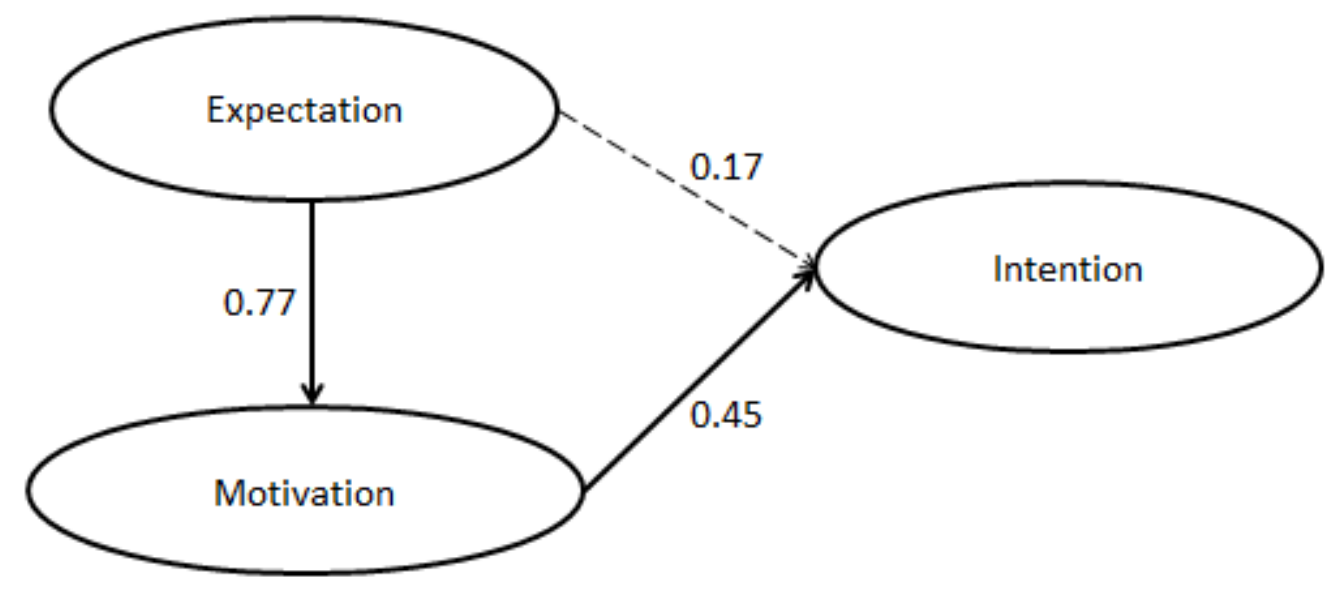

$\longrightarrow$ Significant path at the 0.01 level

$---\rightarrow$ Insignificant path

Figure 2. Structural Model with Estimated Path Coefficients 
Table 1. Respondents' Demographic Profile

\begin{tabular}{|c|c|c|c|}
\hline Characteristics & \multicolumn{2}{|c|}{$\%$ Characteristics } & $\%$ \\
\hline Gender & \multicolumn{2}{|c|}{ Education } & \\
\hline Male & 45.3 & Secondary/High school or below & 3.4 \\
\hline Female & 54.7 & College diploma or university degree & 64.1 \\
\hline Age & \multirow{2}{*}{\multicolumn{2}{|c|}{$\begin{array}{c}\text { Postgraduate or above } \\
\text { 55.2 Total Household Annual Income }\end{array}$}} & 32.5 \\
\hline 25 or below & & & \\
\hline $26-35$ & 32.8 & Under RMB 50,000 & 25.8 \\
\hline $36-45$ & 7.3 & RMB 50,000-RMB 99,999 & 33.2 \\
\hline $46-65$ & 4.7 & RMB 100,000-RMB 149,999 & 17.9 \\
\hline Marital Status & & RMB 150,000-RMB 199,999 & 8.7 \\
\hline Single & 72.8 & RMB 200,000-RMB 249,999 & 2.2 \\
\hline Married with child(ren) & 18.5 & RMB 250,000-RMB 299,999 & 2.6 \\
\hline Married without child(ren) & 8.6 & RMB 300,000-RMB 599,999 & 4.4 \\
\hline Family Size & & RMB 600,000 or above & 5.2 \\
\hline 1 person & 6.9 & & \\
\hline 2 persons & 9.9 & & \\
\hline 3 persons & 43.5 & & \\
\hline 4 persons & 22.4 & & \\
\hline 5 persons & 10.3 & & \\
\hline 6 persons or above & 6.9 & & \\
\hline
\end{tabular}


Table 2. Cruise Preference Profile

Have you ever traveled abroad before (excluding Hong Kong and Macau)? If yes, how many times?

\begin{tabular}{lcll}
\hline None & $69.4 \%$ & 3 times & $2.6 \%$ \\
1 time & $13.6 \%$ & 4 times or above & $8.5 \%$ \\
2 times & $6.0 \%$ & &
\end{tabular}

Which cruise destination(s) would be attractive to you?

\begin{tabular}{lclc}
\hline Southeast Asia & $29.4 \%$ & Europe & $45.0 \%$ \\
Korea & $11.3 \%$ & Middle East & $14.9 \%$ \\
Japan & $18.4 \%$ & Others & $4.3 \%$ \\
America & $25.9 \%$ & None & $5.0 \%$
\end{tabular}

\section{How far in advance would you begin planning your cruise travel?}

\begin{tabular}{llll}
\hline Within 1 month & $18.7 \%$ & $5-6$ months & $17.0 \%$ \\
$1-2$ months & $28.9 \%$ & Longer than 6 months & $19.6 \%$ \\
$3-4$ months & $15.7 \%$ & &
\end{tabular}

What is the most likely channel you would use to book a cruise?

\begin{tabular}{lclc}
\hline Online travel agencies & $33.2 \%$ & Traditional travel agencies & $44.3 \%$ \\
Cruise companies & $21.7 \%$ & Others & $0.9 \%$
\end{tabular}

\begin{tabular}{lclc}
\hline What is your most preferred cruise duration? & \\
\hline $1-3$ days & $3.8 \%$ & $10-15$ days & $27.2 \%$ \\
4-6 days & $16.2 \%$ & Longer than 15 days & $22.6 \%$ \\
$7-9$ days & $30.2 \%$ & & \\
\multicolumn{4}{l}{} \\
\hline \multicolumn{4}{l}{ The most likely number of persons you would like to travel with on a cruise. } \\
Myself & $2.1 \%$ & $7-10$ persons & $7.7 \%$ \\
1-3 persons & $47.4 \%$ & More than 10 persons & $10.3 \%$ \\
\hline
\end{tabular}


Table 3. Exploratory Factor Analysis Results

\begin{tabular}{|c|c|c|c|c|}
\hline Factor & Mean $^{\mathrm{a}}$ & $\begin{array}{c}\text { Factor } \\
\text { Loading }\end{array}$ & $\begin{array}{l}\text { Eigen- } \\
\text { value }\end{array}$ & $\begin{array}{c}\% \text { of } \\
\text { variance }\end{array}$ \\
\hline \multicolumn{5}{|l|}{ Expectation } \\
\hline Active Pursuit & & & 5.096 & 36.91 \\
\hline Not to get seasick & 5.26 & .802 & & \\
\hline Not to be bored & 5.22 & .778 & & \\
\hline Have fun & 6.17 & .743 & & \\
\hline Have good facilities & 5.90 & .732 & & \\
\hline Experience different ways of traveling & 5.88 & 689 & & \\
\hline Get value for money & 5.83 & .685 & & \\
\hline Experience different cuisines & 6.05 & .606 & & \\
\hline Enjoy attractive routes and destinations & 5.97 & .550 & & \\
\hline Serenity & & & 1.291 & 21.15 \\
\hline See some beautiful sceneries & 6.54 & .775 & & \\
\hline Spend time with friends and family & 6.50 & .757 & & \\
\hline Relax & 6.41 & .691 & & \\
\hline \multicolumn{5}{|l|}{ Motivation } \\
\hline Push & & & 3.16 & 52.67 \\
\hline Reduce stress & 5.62 & .838 & & \\
\hline Get spiritual purification and moral enlightenment & 5.26 & .805 & & \\
\hline Escape from routine of work and daily life & 5.41 & .749 & & \\
\hline Have family gathering & 5.25 & .728 & & \\
\hline Accompany family members who want to cruise & 5.49 & .649 & & \\
\hline Talk about trip after returning home & 5.00 & .547 & & \\
\hline Pull & & & 3.302 & 47.17 \\
\hline Enjoy shows and entertainment & 5.10 & .808 & & \\
\hline $\begin{array}{l}\text { Have fun through cruise activities and facilities (e.g. } \\
\text { bar, swimming pool, gym, basketball, jogging, yoga, } \\
\text { karaoke) }\end{array}$ & 5.33 & .766 & & \\
\hline Enjoy luxurious experiences & 5.59 & .715 & & \\
\hline Enjoy spa & 4.66 & .654 & & \\
\hline Build networks & 5.00 & .642 & & \\
\hline Visit friends or relatives who live in the destination & 4.54 & .602 & & \\
\hline Look for excitement & 5.49 & .590 & & \\
\hline Intention & & & 3.34 & 66.81 \\
\hline I'll encourage friends and relatives to go on a cruise & 4.66 & .849 & & \\
\hline I'll recommend a cruise to others & 4.69 & .849 & & \\
\hline I want to cruise sometime in the future & 5.36 & .810 & & \\
\hline I intend to cruise in the next three years & 4.53 & .799 & & \\
\hline I am interested in cruise travel & 5.47 & .778 & & \\
\hline
\end{tabular}

Note: ${ }^{a}$ Scale: 7 = strongly agree, $1=$ strongly disagree . 
Table 4. Goodness-of-fit Indices of CFA Results

\begin{tabular}{lcccccc}
\hline & $\begin{array}{c}\text { Chi-square to degree } \\
\text { of freedom }\end{array}$ & CFI & NFI & GFI & TLI & RMSEA \\
\hline Expectation & 2.509 & .942 & .909 & .930 & .920 & .079 \\
Motivation & 2.370 & .925 & .878 & .916 & .905 & .075 \\
Intention & 3.674 & .980 & .973 & .971 & .960 & .105 \\
Overall measurement model & 1.715 & .984 & .962 & .966 & .974 & .054 \\
\hline
\end{tabular}

Notes: $\mathrm{CFI}=$ comparative fit index; NFI = normed fit index; GFI = goodness-of-fit index; TLI= Tucker Lewis Index; RMSEA= root mean square error of approximation. 
Table 5. Results of the Overall Measurement Model

\begin{tabular}{lccc}
\hline Factor & $\begin{array}{c}\text { Standard Factor } \\
\text { Loading }\end{array}$ & t-value & $\begin{array}{c}\text { Composite } \\
\text { Reliability }\end{array}$ \\
\hline Expectation & .815 & 6.484 & .646 \\
$\quad$ Active Pursuit & .555 & $\mathrm{NA}$ & .749 \\
$\quad$ Serenity & .738 & 9.513 & \\
Motivation & .809 & $\mathrm{NA}$ & \\
$\quad$ Push & & & .863 \\
$\quad$ Pull & .590 & $\mathrm{NA}$ & \\
Intention & .630 & 12.347 & \\
$\quad$ I am interested in cruise travel & .727 & 8.817 & \\
I want to cruise sometime in the future & .879 & 9.679 & \\
I intend to cruise in the next three years & .880 & 9.679 & \\
I'll recommend a cruise to others & & & \\
I'll encourage friends and relatives to go & & & \\
on a cruise &
\end{tabular}


Table 6. Average Variance Extracted (AVE) and Standardized Correlation Matrix for Overall Measurement Model

\begin{tabular}{lccc}
\hline & Motivation & Expectation & Intention \\
\hline Motivation & 1.00 & & \\
Expectation & $.549(.301)$ & 1.00 & \\
Intention & $.497(.247)$ & $.449(.202)$ & 1.00 \\
\hline AVE & .600 & .486 & .564 \\
Mean & 5.221 & 6.095 & 4.940 \\
SD & .920 & .754 & 1.158 \\
\hline
\end{tabular}

Notes: $\mathrm{AVE}=$ average variance extracted; $\mathrm{SD}=$ standard deviation. 